\title{
CO-COMBUSTION OF MISCANTHUS IN A PULVERISED COAL COMBUSTOR: EXPERIMENTS IN A DROPTUBE FURNACE
}

\author{
B. M. WagenaAR and E. J. M. T. Van den Heuvel \\ BTG Biomass Technology Group, Twente University of Technology, P.O. Box 217, 7500 AE, \\ Enschede, The Netherlands
}

(Received 27 November 1995; revised 27 January 1997; accepted 27 January 1997)

\begin{abstract}
In this study, the devolatilisation process of Miscanthus particles inside a pulverised coal combustion chamber is characterised with the aim of finding conditions for which the devolatilisation rate of coal and Miscanthus is similar. However, choosing a power station as an experimental set-up for research is awkward because of the scale of operation ( $\left.>500 \mathrm{MW}_{\mathrm{el}}\right)$. Therefore, BTG has designed and constructed a droptube reactor for well-controlled Miscanthus devolatilisation experiments with operational conditions that resemble those of a pulverised coal combustor. The droptube reactor has an internal diameter of $0.050 \mathrm{~m}$ and a maximum heated length of $1.6 \mathrm{~m}$. Parameters which have been varied are: the droptube temperature $\left(1000^{\circ}, 1200^{\circ}, 1300^{\circ}, 1400^{\circ} \mathrm{C}\right)$; the heated droptube length $(0.4,0.8,1.2$, $1.6 \mathrm{~m}$ ); and the particle size or sieve fraction $(0.6-1,1-2,2-2.8 \mathrm{~mm})$. For a droptube length of $1.6 \mathrm{~m}$, this results in a particle residence time of approximately $1 \mathrm{~s}$.

The experimental study on high-temperature Miscanthus decomposition in the droptube showed that Miscanthus particles which belong to the smallest sieve fraction $(0.6-1 \mathrm{~mm})$ could be devolatilised completely in a $1.6 \mathrm{~m}$ long droptube. Apart from the experimental investigation, a numerical model has been developed. Samples of Miscanthus particles, representing grass-/straw-like crops, have been characterised in detail with respect to their size distribution. These data have been used to validate the numerical model with the results from the droptube experiments. The validation was successful. The model was then applied to predict the Miscanthus devolatilisation behaviour in a pulverised coal power station. The model predicts full conversion of Miscanthus particles for particles with a diameter smaller than $3 \mathrm{~mm}$, in the core of the coal flame. Feeding of Miscanthus particles with a diameter up to $3 \mathrm{~mm}$ can therefore be recommended. Miscanthus particles with a diameter larger than $3 \mathrm{~mm}$ contribute to a geometrical extension of the coal flame in the upward direction. This should be avoided and firing of such large particles in a pulverised coal combustor is discouraged. Copyright (C) 1997 Published by Elsevier Science Ltd
\end{abstract}

\section{NOMENCLATURE}

Furnace cross-sectional area $\left[\mathrm{m}^{2}\right]$
Thermal heat capacity $\left[\mathrm{J} \mathrm{kg}^{-1} \mathrm{~K}^{-1}\right]$

Drag coefficient [-]

Particle cylinder diameter [m]

Excess air amount [-]

Gravitational constant $(9.81)\left[\mathrm{m} \mathrm{s}^{-2}\right]$

Galileo number [-]

Enthalpy per unit mass [ $\left.\mathrm{J} \mathrm{kg}^{-1}\right]$

Caloric value per unit mass [ $\left.\mathrm{J} \mathrm{kg}^{-1}\right]$

Furnace height [m]

Heat of reaction $\left[\mathrm{J} \mathrm{kg}^{-1}\right]$

First-order wood decomposition rate constant $\left[\mathbf{s}^{-1}\right]$

Particle cylinder length [m]

Particle mass [kg]

Mass flow [kg s-1]

Nusselt number $\left(\alpha d_{p} / \lambda_{1}\right)[-]$

Rate of energy production, power [W]

Prandtl number $\left(\eta_{8} C_{8} / \lambda_{8}\right)[-]$

Gas-to-particle heat flow [W]

Cylinder radius [m]

Universal gas constant $\left[\mathrm{J} \mathrm{mol}^{-1} \mathrm{~K}^{-1}\right]$

Reynolds number $\left(\rho_{\mathrm{g}} v_{\mathrm{p}} d_{\mathrm{p}} / \eta_{\mathrm{s}}\right)[-]$

Temperature [K]

Velocity [ $\left.\mathrm{m} \mathrm{s}^{-1}\right]$
$X_{\mathrm{p}} \quad$ Axial particle position in the droptube [m]

\section{Greek symbols}

$\alpha \quad$ Gas-to-particle heat transfer coefficient

$\left[\mathrm{W} \mathrm{\textrm {m } ^ { - 2 }} \mathrm{K}^{-1}\right]$

$\varepsilon \quad$ Particle emissivity coefficient [-]

$\Phi_{c} \quad$ Final char mass fraction after pyrolysis

(0.10) [-]

$\eta \quad$ Viscosity [Pa s]

$\lambda$ Thermal conductivity [W $\left.\mathbf{~ m}^{-1} \mathrm{~K}^{-1}\right]$

$\mu \quad$ Molar mass [ $\left.\mathrm{kg} \mathrm{mol}^{-1}\right]$

$\rho \quad$ Density $\left[\mathrm{kg} \mathrm{m}^{-3}\right]$

$\sigma \quad$ Stefan-Boltzmann constant $\left(5.67 \times 10^{-8}\right)$

$\left[\mathrm{kg} \mathrm{s}^{-3} \mathrm{~K}^{-4}\right]$

$\xi \quad$ Efficiency $[-]$

\section{Subscripts}

air Air

av Average

biom Biomass

coal Coal

el Electric

G Gas phase

misc Miscanthu

p Particle

$t$ Terminal

th Thermal 


\section{INTRODUCTION}

Co-combustion of biomass with coal has recently attracted wide interest as a means to reduce coal consumption, while maintaining equal power station output. The replacement of coal by biomass reduces the emission of $\mathrm{CO}_{2}$ which could act as a greenhouse gas in the Earth's atmosphere. This is especially the case when energy crops are considered. Energy crops, such as Miscanthus, are a renewable energy resource. The $\mathrm{CO}_{2}$ emitted during combustion of the crop is absorbed by the new growing crop, thus closing the $\mathrm{CO}_{2}$ cycle. Furthermore, biomass contains only small amounts of fixed nitrogen and sulphur compared with coal on a weight basis, which reduces the emission of $\mathrm{NO}_{x}$ and $\mathrm{SO}_{x}$ upon combustion.

By introduction of biomass into the pulverised coal combustion process, a new material is added with a different chemical reactivity and particle size. Before applying biomass as a feedstock for the combustion process, the combustion process of this feedstock should be characterised with the aim of designing proper biomass feeding systems and the exact location of these feeders in the coal combustor. Analysis of the biomass combustion process can also be used to detect operational problems beforehand. However, measurement of the thermal devolatilisation rate of biomass particles in a full-scale coal combustor is difficult due $o$ the size of this operation and commercial interests which only allow the variation of combustion parameters, like temperature and excess air amount, in restricted ranges. Therefore, a laboratory-scale droptube reactor has been designed and built to investigate the devolatilisation process of biomass in detail. A special feature of this droptube is the omission of carrier gas, which invariably introduces hydrodynamic entrance and exit effects, along with a usually unknown gas-phase velocity profile inside the droptube. Bitowft et al. ${ }^{1}$ published a study concerning the fast pyrolysis of biomass in a droptube reactor, while Hallgren et $a .^{2}{ }^{2}$ published results on the topic of gasification of biomass in a droptube reactor. This paper covers the combustion of Miscanthus particles in a droptube reactor under conditions approximately similar to those of a pulverised coal combustor. A numerical model has been developed and validated for these conditions. Then, the Miscanthus combustion model is applied to the situation of cofiring in a $80 \mathrm{MW}_{\mathrm{el}}$ power station by introducing published conditions for this station into the model.

The activities carried out are part of projects under two research programmes in which Miscanthus as sustainable energy crop is being investigated. These programmes are the National Research Programme on Global Air Pollution and Climate Change, and the European Miscanthus Network, a project funded under the EC-AIR Programme. The projects have been financially supported by the Energy from Waste and Biomass Programme of the Netherlands Agency for Energy and Environment.

In Section 2, a short introduction on coal combustion is presented. Section 3 describes the experimental methodology for the tests in the droptube. In Section 4, the numerical model developed for investigating the combustion behaviour of Miscanthus particles is discussed. In Section 5, the experimental and numerical model results are presented and reviewed. In Section 6 finally, a description is given of how the numerical model is applied for co-combustion simulations in a particular pulverised coal combustor.

\section{BACKGROUND ON COAL COMBUSTION}

The chemical nature of coal can be simplified reasonably by assuming coal to consist completely of carbon. Combustion of this simplified coal type, which quite resembles anthracite, can then be described by:

$$
\begin{aligned}
\mathrm{C}+\mathrm{O}_{2}+4 \mathrm{~N}_{2} \rightarrow & \mathrm{CO}_{2}+4 \mathrm{~N}_{2} \\
& +393 \mathrm{~kJ} \text { (exothermal). }
\end{aligned}
$$

Complete stoichiometric combustion of $1 \mathrm{~kg}$ coal would require $12 \mathrm{~kg}$ of air, although power stations usually add excess air to the stoichiometric air amount to avoid the emission of carbon monoxide due to poor gas-phase mixing.

Today, a number of combustion reactor types are available to convert the caloric value of coal into heat and combustion products. These reactor types consist of pulverised coal combustors, stoker combustors, atmospheric fluidised-bed combustors, and circulating fluidised-bed combustors. However, pulverised coal combustion is the technique which has been 
Table 1. Parameters characterising Goudey Station

\begin{tabular}{lc}
\hline Main parameters & \\
Furnace height, $H_{\mathrm{f}}$ & $21.5 \mathrm{~m}$ \\
Furnace cross sectional area, $A_{\mathrm{f}}$ & $57.8 \mathrm{~m}^{2}$ \\
Coal feed rate, $\boldsymbol{M}_{\mathrm{coal}}$ & $6.2 \mathrm{~kg} \mathrm{~s}^{-1}$ \\
Air feed rate, $\boldsymbol{M}_{\mathrm{air}}$ & $90 \mathrm{~kg} \mathrm{~s}^{-1}$ \\
Thermal output, $\boldsymbol{P}_{\mathrm{th}}$ & $200 \mathrm{MW}_{\mathrm{th}}$ \\
Net electrical power, $P_{\mathrm{el}}$ & $61.2 \mathrm{MW}_{\mathrm{el}}$ \\
Power station efficiency & $31.7 \%$ \\
Additional parameters & \\
Coal caloric value, $\boldsymbol{H}_{\text {coal }}$ & $31.2 \mathrm{MJ} \mathrm{kg}$ \\
Excess air amount, $E_{\text {air }}$ & 0.214 \\
Average gas phase temperature, $T_{\mathrm{av}}$ & $1600 \mathrm{~K}$ \\
Average upward gas velocity & $7.1 \mathrm{~m} \mathrm{~s}^{-1}$ \\
\hline
\end{tabular}

applied most when large-scale power-generation operations (i.e. $>500 \mathrm{MW}_{\mathrm{el}}$ ) are considered.

Processes which govern the combustion of pulverised coal inside a combustor can be interpreted and understood if this process is locally probed, aiming to measure relevant process parameters like the temperature, velocity and local composition of the gas and solid phase. Germane et al. ${ }^{3}$ provide the most complete information concerning full-scale coal combustion which is available in the open literature. Their subject under study was the $80 \mathrm{MW}_{\mathrm{el}}$ Goudey Station of the New York State Electricity and Gas Company. From the published data of Germane et al., ${ }^{3}$ Test 2 has been selected. This test can be characterised by the operating parameters presented in Table 1.

According to Benson et al., the surface tension between the slag phase and the char phase is sufficiently high to prevent wetting of the char surface with a slag layer. This condition applies both for burning coal and Miscanthus.

\section{EXPERIMENTAL METHODOLOGY}

\subsection{Introduction}

The objective of this study is to support the research in cofiring of Miscanthus in pulverised coal combustors. Literature on this topic is scarce and insufficient to construct a reliable theoretical model to predict the rate of Miscanthus devolatilisation in power plants. Therefore, an experimental set-up has been designed and constructed, as well as a measurement programme. In the set-up, the decomposition of Miscanthus at the high temperatures encountered in pulverised coal firing can be studied.

The droptube reactor has been selected as an instrument for the simulation of the environment inside the pulverised coal combustion chamber. Default values for experimental conditions such as temperature, particle residence time and gas-phase composition have been derived from pulverised coal combustion literature. Only the Miscanthus particle size is an independent variable which has been defined during the experiments.

\subsection{The experimental set-up}

A droptube reactor has been constructed by BTG with the aim of emulating the rapid devolatilisation of biomass in a well-defined and controlled environment. The reactor tube has an internal diameter of $50 \mathrm{~mm}$ and a heated tube length varying from 0.4 to $1.6 \mathrm{~m}$. The current maximum operation temperature of $1400^{\circ} \mathrm{C}$ is limited by the quality of the insulating material and can be extended to $1800^{\circ} \mathrm{C}$ if necessary. Four identical heated sections can be stacked on top of each other, which yields heated tube lengths of $0.4,0.8,1.2$ and $1.6 \mathrm{~m}$, respectively. The axial temperature difference along the tube is less then $20^{\circ} \mathrm{C}$ for reactor temperatures varying between $800^{\circ}$ and $1400^{\circ} \mathrm{C}$. A schematic representation of the droptube reactor is given

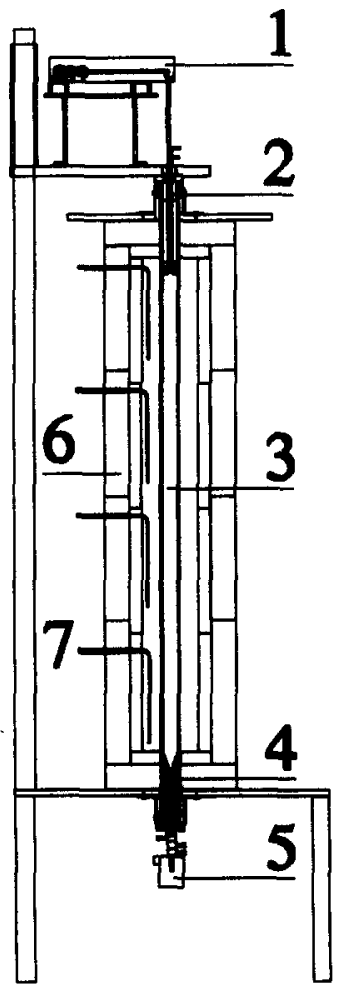

Fig. 1. Schematic representation of the experimental set-up, which shows the droptube as item 3. 
in Fig. 1. The optical particle sensors at the droptube entrance and exit are not represented in this figure; these sensors are employed in the particle residence time measurements. Another feature of this reactor is its small thermal mass and, as a result, the reactor is isothermal within $2 \mathrm{~h}$ after a step change in its operating temperature up to $1400^{\circ} \mathrm{C}$.

The figure shows (1) a biomass belt feeder, (2) a water-cooled entrance, (3) the alumina droptube, (4) a water-cooled exit, (5) the nitrogen-cooled solid-product collection vessel, (6) insulating sections, and (7) an electrical heating element.

To study the thermal decomposition rate of single Miscanthus particles, a continuous and constant Miscanthus feeding rate of $1 \mathrm{~g} \mathrm{~h}^{-1}$ has been applied. For this purpose, a customised biomass belt feeder has been designed. The belt feeder can even be used in a single particle feeding mode which is used in the particle residence time measurements.

\subsection{Demarcation of the experimental pro- gramme}

The parameters which can be varied in a biomass conversion experiment are:

- the gas phase temperature;

- the gas phase composition;

- the particle residence time at a high temperature (read axial droptube length); and

- the Miscanthus particle size.

Default values of the first three parameters have been derived from the conditions encountered in a pulverised coal combustion chamber, which have been obtained from literature studies to be presented hereafter. The Miscanthus particle size is subject to the condition of complete conversion at the end of the droptube of maximum length, since this corresponds to a desirable complete conversion of Miscanthus in the power plant.

3.3.1. Temperature selection. Chomiak ${ }^{5}$ and Benson et $a l .^{4}$ report temperatures in a pulverised coal combustor which vary between 1273 and $1873 \mathrm{~K}$. Droptube test temperatures equal to 1273,1473 and $1673 \mathrm{~K}$ are therefore recommended. It should be noted that the current maximum droptube temperature is limited to $1673 \mathrm{~K}$.

3.3.2. Gas phase selection. $\mathrm{Gumz}^{6}$ and Germane et al. ${ }^{3}$ both published air stoichi- ometry coefficients in pulverised coal combustion with a value of approximately 1.20 . This implies that oxygen is present everywhere in the combustion furnace. For a given char, Walker et al. ' have estimated the relative rate, $R$, of char oxidation and gasification using various reactive gases with a partial pressure of 0.1 bar at $1073 \mathrm{~K}$ as:

$$
\begin{aligned}
& R_{\mathrm{O}_{2}}=10^{5} \gg R_{\mathrm{H}_{2} \mathrm{O}}=2>R_{\mathrm{CO}_{2}} \\
& \quad=1 \gg R_{\mathrm{H}_{2}}=3 \times 10^{-3} .
\end{aligned}
$$

With oxygen present, the char and probably Miscanthus gasification reaction rates compared with oxygen are negligible. Therefore, only variation of the oxygen concentration in the droptube atmosphere is an interesting parameter, and its value has been chosen equal to $20 \mathrm{vol} \%$ (thus air is an oxidising initial gas).

3.3.3. Droptube length. The residence time of coal particles in a pulverised coal combustion chamber is about $1 \mathrm{~s}$, according to data provided by Benson et al. ${ }^{4}$ These $100 \mu \mathrm{m}$ diameter pulverised coal particles move essentially with the gas-phase velocity. Also, for Miscanthus particles, a velocity approximately equal to the gas-phase velocity is assumed for reasons of a well-defined biomass flow. Suppose that the upward velocity of the Miscanthus particles is significantly smaller than the gas-phase velocity; downward raining of Miscanthus particles could occur, and partly converted Miscanthus particles would be collected in the ash box. An equal coal and Miscanthus velocity implies equal residence times of about $1 \mathrm{~s}$ in the combustion chamber. This residence time can be achieved in a droptube with an axial length of $1 \mathrm{~m}$, as predicted by a cold flow model. Recommended tube lengths are $0.4,0.8,1.2$ and $1.6 \mathrm{~m}$.

3.3.4. Miscanthus particle diameter. The particle diameter is chosen as small as possible to ensure rapid and complete devolatilisation of the Miscanthus particles. If $90 \mathrm{wt} \%$ of a Miscanthus sample has a particle size less than a specified diameter, then this diameter is called the upper particle diameter (UPD). Knoef and Prins ${ }^{8}$ have shown that milling coarse wood to an UPD of $0.8 \mathrm{~mm}$ results in milling costs equal to $25 \mathrm{ECU} /$ ton biomass. Milling of wood to obtain a feedstock with a UPD of $0.1 \mathrm{~mm}$ results in $75 \mathrm{ECU} /$ ton biomass milling costs, which is not believed to be economically feasible. For the droptube exper- 
iments, Miscanthus particle diameters of 0.5 , 1 and $2 \mathrm{~mm}$ are recommended.

The experimental conditions may be summarised as follows:

$\begin{array}{ll}\text { Temperatures: } & 1000^{\circ}, 1200^{\circ}, 1300^{\circ} \text { and } \\ & 1400^{\circ} \mathrm{C} . \\ \begin{array}{l}\text { Oxygen } \\ \text { concentration: }\end{array} & 20 \mathrm{vol} \% . \\ \text { Particle size class: } & 0.5-1,1-2,2-3 \mathrm{~mm} . \\ \text { Tube length: } & 0.4,0.8,1.2 \text { and } 1.6 \mathrm{~m} . \\ \text { Biomass type: } & \text { Miscanthus. }\end{array}$

\subsection{Operating the droptube reactor}

3.4.1. Pretreatment procedures. Prior to each experiment, Miscanthus is size reduced using a Peppink $0.25 \mathrm{~m}$ diameter hammermill, with four rotating hammers operating at 2800 r.p.m. The circular openings of the hammermill sieve have a diameter of $3 \mathrm{~mm}$ and the fraction of free sieve area is approximately $10 \%$. Because of the large spread in particle size obtained, all material is size-classified with a vibrating sieve stack. The mesh sizes of the sieves are $2.8 \mathrm{~mm}$ for the top sieve, $2.0 \mathrm{~mm}, 1.0 \mathrm{~mm}$ and $0.595 \mathrm{~mm}$ for the bottom sieve; upon sieving, three Miscanthus particle size classes are obtained:

$\begin{array}{ll}\text { Class I } & 0.6-1.0 \mathrm{~mm} \\ \text { Class II } & 1.0-2.0 \mathrm{~mm} \\ \text { Class III } & 2.0-2.8 \mathrm{~mm} .\end{array}$

After milling and sieving, the obtained material has been dried to $0 \%$ moisture.

3.4.2. An experiment. Each experiment starts with the weighing of $0.5 \mathrm{~g}$ Miscanthus of a specified size class. Carrier gas has not been applied in the experiments to avoid hydrodynamic entrance and exit effects, whose flow patterns and axial length are difficult to quantify. Because of the omission of carrier gas, feeding of the Miscanthus particles lasted for a period which was chosen such that the gas-phase concentration of each component initially present did not change by more than $10 \%$. This is equivalent to a maximum production of $10 \mathrm{vol} \%$ of gaseous Miscanthus decomposition products. Then feeding stopped and the droptube was flushed with initial composition gases. The flushing volume was chosen as a factor of 5 higher than the droptube volume and, after flushing, feeding of the Miscanthus particles was resumed. This cyclic Miscanthus feeding and gas flushing operation lasted for half an hour, and the solid product was collected continuously in a downstream-positioned solid-product collection vessel.

3.4.3. Post processing. Partially decomposed solid products were collected and their weight was measured on a balance with a precision of $10^{-4} \mathrm{~g}$. The mass conversion of Miscanthus is defined as:

Conversion $=$

(initial Miscanthus weight) (solid products weight)

(initial Miscanthus weight)

\section{MODELLING OF THE MISCANTHUS DECOMPOSITION PROCESS IN A DROPTUBE}

\subsection{Introduction}

The ultimate goal of the Miscanthus decomposition model is to describe the processes which occur inside a pulverised coal combustion station, and which is of more importance, to assess if Miscanthus contributes to the flame formation inside the combustion chamber. Visual inspection of the solid products which are being formed during the high-temperature biomass conversion process showed that Miscanthus particles decompose in two stages. First, Miscanthus quickly devolatilises and only $10 \mathrm{wt} \%$ of char remains. These volatiles contain more than $80 \%$ of the calorific value of the original Miscanthus. ${ }^{9}$ The second stage consists of the slow combustion of char. Since the devolatilisation of the Miscanthus particles is of prime importance in the flame formation inside a pulverised coal combustor chamber, this model describes only the devolatilisation stage due to rapid pyrolysis reactions as has been observed in the experimental programme.

A model to calculate the Miscanthus conversion on a weight basis as a function of the axial position in a heated droptube has been developed to gain insight into the processes which govern the rate of devolatilisation of Miscanthus particles at elevated temperatures. This model is represented by a closed set of equations which describe and represent all relevant physical phenomena which occur during combustion of Miscanthus. First, transport equations are presented which treat the particle as a whole, then balances are presented which describe the thermochemical phenomena inside the particle. 


\subsection{Particle motion equations}

The equations which describe the falling motion of particles inside the droptube are derived from Newton's laws. Equatioon (3) relates the change in particle position to particle speed. Equation (4) relates the particle acceleration to the force of gravity and the drag force on a falling particle.

$$
\begin{gathered}
\frac{\mathrm{d} X_{\mathrm{p}}}{\mathrm{d} t}=v_{\mathrm{p}} . \\
m_{\mathrm{p}} \frac{\mathrm{d} v_{\mathrm{p}}}{\mathrm{d} t}=m_{\mathrm{p}} g_{z}-C_{\mathrm{d}} A_{\mathrm{p}} \frac{1}{2} \rho_{\mathrm{air}} v_{\mathrm{p}}^{2},
\end{gathered}
$$

\subsection{Particle radial balances}

The behaviour of a single particle upon external heating is given by a Miscanthus and a char mass balance together with a thermal energy balance. Due to the cylindrical shape of the hammermilled Miscanthus particles, these balances are given in cylindrical coordinates, as represented in Fig. 2. The balances are given respectively by:

$$
\begin{gathered}
\frac{\partial \rho_{\mathrm{w}}}{\partial t}=-k \rho_{\mathrm{w}} . \\
\frac{\partial \rho_{\mathrm{c}}}{\partial t}=\phi_{\mathrm{c}} k \rho_{\mathrm{w}}, \\
\left(\rho_{\mathrm{w}}+\rho_{\mathrm{c}}\right) C_{\mathrm{p}, \mathrm{w}} \frac{\partial T}{\partial t}=\frac{1}{r} \frac{\partial}{\partial r} r \lambda \frac{\partial T}{\partial r}-k \rho_{\mathrm{w}} H_{\mathrm{r}},
\end{gathered}
$$

Solutions of these equations are the density distribution of char and unconverted wood inside a particle, and the temperature profile inside a particle. The particle mass, used in eqn (4) can be derived from the density distribution by applying eqn (8).

$$
m_{\mathrm{p}}=L_{\mathrm{p}} \int_{0}^{d_{\mathrm{p}} / 2}\left(\rho_{\mathrm{w}}+\rho_{\mathrm{c}}\right) 2 \pi r \mathrm{~d} r .
$$

Apart from the transport equations (5-7), boundary equations have to be supplied which link the particle to its surroundings.

\subsection{Boundary condition}

A particle submerged in a gas flow is only coupled to its surroundings by its surface. At this surface, the heat flows outside the particle due to forced convection and radiation are in equilibrium with the conductive heat flow inside the particle:

$$
\begin{array}{r}
\alpha\left(\left.T_{\mathrm{p}}\right|_{\left(r=\frac{1}{2} d_{\mathrm{p}}\right)}-T_{\mathrm{g}}\right)+\sigma\left(\left.T_{\mathrm{p}}^{4}\right|_{\left(r=\frac{1}{2} d_{\mathrm{p}}\right)}-T_{\mathrm{g}}^{4}\right)= \\
\left.\lambda \frac{\partial T}{\partial r}\right|_{\left(r=\frac{1}{2} d_{\mathrm{p}}\right)} .
\end{array}
$$

\subsection{Constitutive equations}

The constitutive equations consists of supplementary relations for the transport coefficients such as the drag coefficient for a cylindrical particle and the gas-to-particle heat transfer coefficient. Apart from the transport coefficients, the Miscanthus decomposition kinetics also have to be defined.

4.5.1. The drag coefficient. According to Becker, ${ }^{10}$ free-falling cylindrical particles tend to orient themselves with their flat side forwards, perpendicular to the gas flow direction if the particle Reynolds number exceeds a value of 5.5. The drag coefficient of a particle is dependent on the particle Reynolds number,

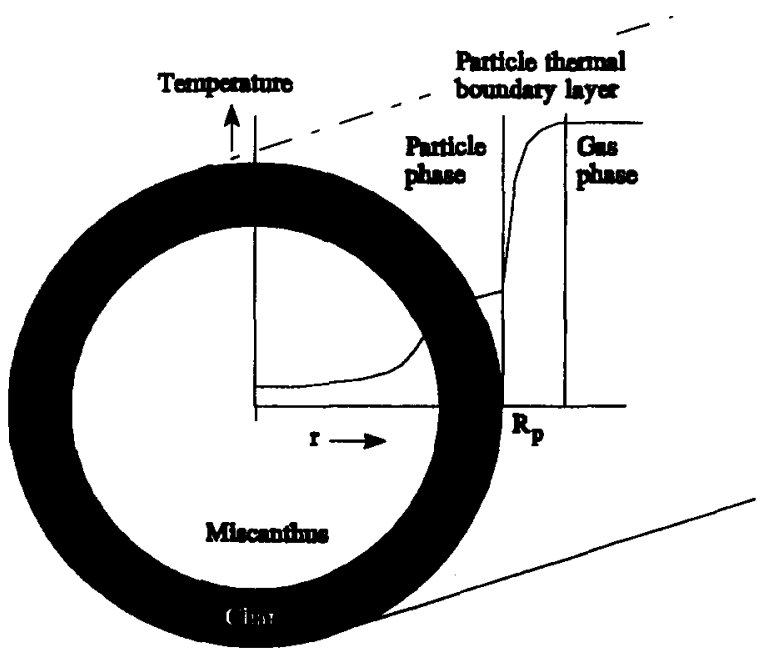

Fig. 2. The particle in cylindrical coordinates (axisymmetry is assumed). 
and an empirical correlation between both quantities was obtained by Lapple and Shepherd." The Reynolds number for cylindrical particles moving with their axis normal to the gas flow direction is given by:

$$
R e_{\mathrm{p}}=\frac{\rho v D_{\mathrm{p}}}{\eta} .
$$

Lapple and Shepherd" published drag coefficient measurements for the Reynolds range: $10^{-4}<R e_{\mathrm{p}}<10^{5}$. This drag coefficient correlation and its application in the drag force equation are given by:

$$
\begin{gathered}
C_{\mathrm{d}}=1.2+3.3 R e_{\mathrm{p}}^{-0.5}+6.3 R e_{\mathrm{p}}^{-0.9}, \\
F_{\mathrm{d}}=C_{\mathrm{d}} D_{\mathrm{p}} L_{\mathrm{p}} \frac{1}{2} \rho v^{2} .
\end{gathered}
$$

4.5.2. The gas-to-particle heat transfer coefficient. Measurements of the gas-to-cylinder heat transfer coefficient have been published by Collis and Williams, ${ }^{12}$ and Whitaker ${ }^{13}$ for gas flowing perpendicular to the cylinder axis. Their measurements cover the Reynolds range $10^{-3}<R e_{\mathrm{p}}<10^{5}$, and a correlation of their measurements yields:

$$
N u_{\mathrm{p}}=0.24+0.56 R e_{\mathrm{p}}^{0.45}+0.06 R e_{\mathrm{p}}^{0.66} .
$$

The gas-to-particle heat flow depends on the particle Nusselt number and the temperature difference between the gas phase and the particle surface:

$$
Q_{\mathrm{p}}=\pi N u_{\mathrm{p}} \lambda_{\mathrm{g}} L_{\mathrm{p}}\left(T_{\mathrm{g}}-T_{\mathrm{p}, r=\frac{1}{2} d_{\mathrm{p}}}\right) .
$$

4.5.3. Miscanthus decompositions kinetics. Visual inspection of the solid products which were collected at the droptube exit showed that the collected particles had a black and charred texture. A second experiment in which the particle was monitored inside the droptube showed that a $1 \mathrm{~mm}$ diameter and $10 \mathrm{~mm}$ long Miscanthus particle released its volatiles uniformly, and a burning volatiles envelope formed around the particle with a diameter of $5 \mathrm{~mm}$ and a length of $15 \mathrm{~mm}$. The observation of charred product particles showed that the rapid decomposition of Miscanthus occurred by a pyrolysis mechanism inside the particles and combustion of the volatiles outside a decomposing particle.

The decomposition rate of Miscanthus at various temperatures could not be obtained from the literature at the moment of writing of this paper. Therefore, the published thermal decomposition rate expressions of other biomass types have been screened for use as a substitute for the unknown Miscanthus decomposition rate equation. We selected a study by Wagenaar et al. ${ }^{14}$ who published a rate equation of pine wood pyrolysis in the temperature range from 573 to $873 \mathrm{~K}$. Their single first-order decomposition rate constant is given by the following Arrhenius type of equation:

$$
k=1.4 \times 10^{10} \exp \left(-150 \times 10^{3} / R T\right) .
$$

If, at a temperature higher than $700^{\circ} \mathrm{C}$, eqn (15) predicts values which exceed 100 , a limiting value of 100 is used in the calculations, because higher values have not yet been demonstrated in the literature. This assumption does not influence the simulation results, which clearly showed heat transfer limitations.

\subsection{Model results}

The mathematical model defined by eqns (3) (15) has been used to simulate the thermal decomposition of Miscanthus particles. All necessary model parameter values are given in Table 2.

The numerical simulation program calculates the disappearance in time of Miscanthus and the formation of char inside a particle. Both quantities are presented in Fig. 3 for a particle which has been subject to the hot combustion conditions for $0.5 \mathrm{~s}$.

On the horizontal axis of Fig. 3, the cylinder radius is given. A cylinder radius equal to 0 corresponds to the centre of the cylinder, whereas a radius equal to $0.50 \mathrm{~mm}$ corresponds to the cylinder surface. Miscanthus and char density profiles inside a cylindrical particle are given on the vertical axis on the left-hand side. The temperature profile as a function of the radius is given on the right-hand side. From Fig. 3, it can be recognised that for radii larger than $0.3 \mathrm{~mm}$ only char is present. For radii smaller than $0.2 \mathrm{~mm}$, only Miscanthus is present with its initial density, and it appears that the chemical decomposition volume only exists in

Table 2. Additional model parameters

\begin{tabular}{lc}
\hline Miscanthus particle shape & Cylindrical \\
Miscanthus particle diameter & $1.0 \mathrm{~mm}$ \\
Miscanthus particle length & $10 \mathrm{~mm}$ \\
Miscanthus density & $300 \mathrm{~kg} \mathrm{~m}^{-3}$ \\
Miscanthus heat capacity & $1335 \mathrm{~J} \mathrm{~kg}^{-1} \mathrm{~K}^{-1}$ \\
Miscanthus heat conductivity & $0.08 \mathrm{~W} \mathrm{~m}-1 \mathrm{~K}^{-1}$ \\
Heat of reaction & $0.5 \mathrm{MJ} \mathrm{kg}$-1 \\
Ultimate & 0.1 \\
Gas-phase medium & $\mathrm{Air}$ \\
Gas-phase temperature & $1573 \mathrm{~K}$ \\
\hline
\end{tabular}




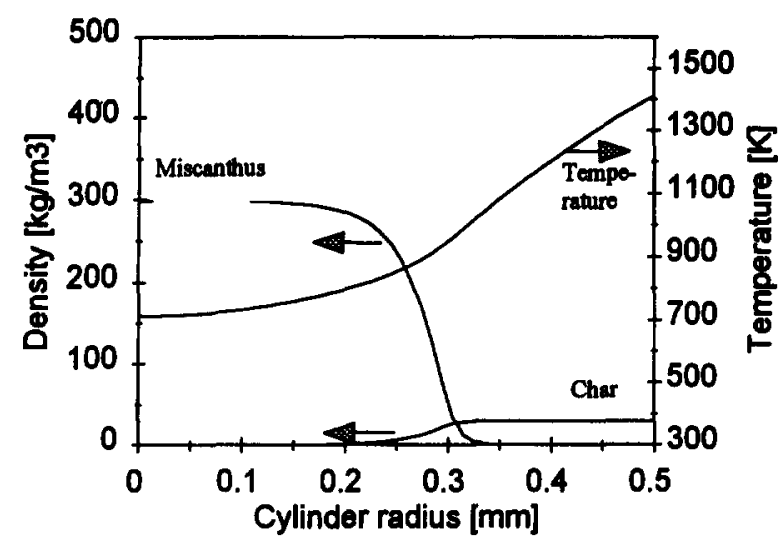

Fig. 3. Miscanthus and char density profiles inside a decomposing Miscanthus particle (left). The temperature profile is included in this graph (right).

the radii range from 0.2 to $0.3 \mathrm{~mm}$ where both Miscanthus and char are present. The temperature inside the particle varies from $700 \mathrm{~K}$ in the particle centre to $1400 \mathrm{~K}$ at the particle surface. The overall Miscanthus conversion of the particle shown in Fig. 3 is $70 w t \%$.

The mass conversion of a Miscanthus particle in the droptube is given in Fig. 4. A mass conversion equal to 0 corresponds to the original Miscanthus particle and a mass conversion equal to 1 corresponds to a char particle.

The particle first falls for $0.05 \mathrm{~s}$, or $0.1 \mathrm{~m}$, in the droptube without any conversion. This interval corresponds to the heating of the surface (and interior) of the Miscanthus particle to the temperature of rapid pyrolysis (approximately $800 \mathrm{~K}$ ). Then, the particle starts to decompose until at an axial position of $0.8 \mathrm{~m}$ it is completely decomposed.

\section{EXPERIMENTAL AND NUMERICAL RESULTS}

\subsection{Miscanthus feedstock analysis}

Miscanthus stems have first been hammermilled according to the pretreatment procedures outlined in Section 3.4. After hammermilling, the Miscanthus particles have been sizeclassified; the mesh size of the sieves are $2.8 \mathrm{~mm}$ for the top sieve, $2.0 \mathrm{~mm}, 1.0 \mathrm{~mm}$ and $0.595 \mathrm{~mm}$ for the bottom sieve. Upon sieving, three Miscanthus particle size classes are obtained:

$\begin{array}{ll}\text { Class I: } & 0.6-1.0 \mathrm{~mm} \\ \text { Class II: } & 1.0-2.0 \mathrm{~mm} \\ \text { Class III: } & 2.0-2.8 \mathrm{~mm} .\end{array}$

Visual inspection of the Miscanthus particles of each size class showed that the shape of hammermilled particles is nearly cylindrical. A random sample of 35 class II particles has been

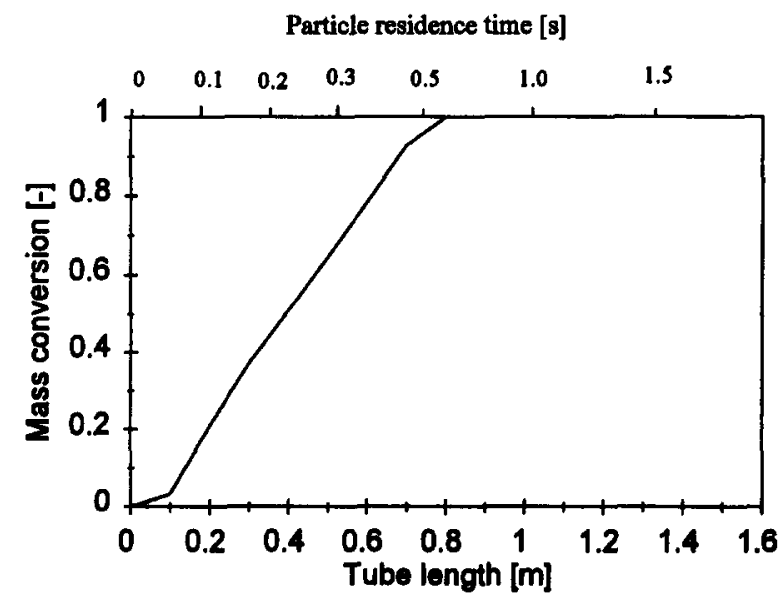

Fig. 4. Mass conversion of a $1 \mathrm{~mm}$ diameter and $10 \mathrm{~mm}$ long cylindrical Miscanthus particle vs the axial droptube position. 


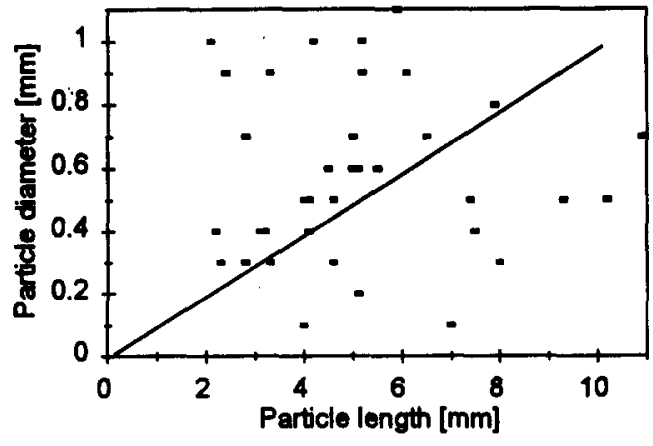

Fig. 5. Class II Miscanthus particle size distribution defined by the length and diameter of each cylindrical particle.

studied in detail and the results obtained are presented in Figs 5 and 6.

The solid line in Fig. 5 represents the particles with a length-to-diameter ratio equal to 10 . According to the cloud of particle coordinates shown in Fig. 5, it appears that hammermilling and subsequent sieving of the Miscanthus particles results in a poorly defined particle-size distribution.

The horizontal coordinate in Fig. 6 represents each individual particle. If, for instance, particle number 14 is selected (vertical dotted line in Fig. 6), its size can be obtained by the intercept of the horizontal solid line in Fig. 6 and the vertical axis on the right-hand side. This yields a value of the cylinder diameter equal to $0.7 \mathrm{~mm}$. Using a similar procedure, the accumulative volume fraction of particles 1-14 can be found on the left-hand axis, which yields an accumulative volume fraction equal to $75 \mathrm{vol} \%$.

Figure 6 shows that the largest half of the particle sample contains more than $75 \%$ of the total particle volume. Hence, the thermal conversion of a biomass size class is rate limited by these large particles. Since hammermilling and sieving are realistic large-scale biomass pretreatment operations, it has been decided to model numerically the decomposition of a single cylindrical Miscanthus particle with a unique diameter and length. However, the thermal decomposition of a real particle distribution can be predicted by superposition of the outcomes of a numerical model run in series with the particle length-diameter coordinates as input.

\subsection{Measured Miscanthus conversion and model validation}

Size analysis measurements of class II Miscanthus particles showed that hammermilling of grassy biomass and subsequent sieving results in a poorly defined particle distribution. For calculation purposes, the complex size distribution was simplified using the analysis data of the previous section.

Class I: $75 \mathrm{wt} \%, d_{\mathrm{p}}=0.6 \mathrm{~mm}, L_{\mathrm{p}}=6 \mathrm{~mm}$ and $25 \mathrm{wt} \%, d_{\mathrm{p}}=0.3 \mathrm{~mm}, L_{\mathrm{p}}=3 \mathrm{~mm}$;

Class II: $75 \mathrm{wt} \%, d_{\mathrm{p}}=1 \mathrm{~mm}, L_{\mathrm{p}}=10 \mathrm{~mm}$ and $25 \mathrm{wt} \%, d_{\mathrm{p}}=0.5 \mathrm{~mm}, L_{\mathrm{p}}=5 \mathrm{~mm}$;

Class III: $75 \mathrm{wt} \%, d_{\mathrm{p}}=1.6 \mathrm{~mm}, L_{\mathrm{p}}=$ $16 \mathrm{~mm}$ and $25 \mathrm{wt} \%, d_{p}=0.8 \mathrm{~mm}, L_{\mathrm{p}}=0.8 \mathrm{~mm}$.

All three size classes of hammermilled Miscanthus have been fed into the droptube reactor. Graphs of the measured mass conversion as a function of the droptube length are presented in Figs 7 and 8. Respectively, they present the droptube conversion results for the particles belonging to size class I and the sieve fraction from 0.6 to $1 \mathrm{~mm}$, and size class III and sieve fraction from 2 to $2.8 \mathrm{~mm}$.

From Fig. 7, it can be observed that a complete conversion of the biomass particles can be achieved for a droptube length larger than $1 \mathrm{~m}$. The model predictions seem to deviate rather a lot from the measured data points. This can be attributed to the unknown thermal

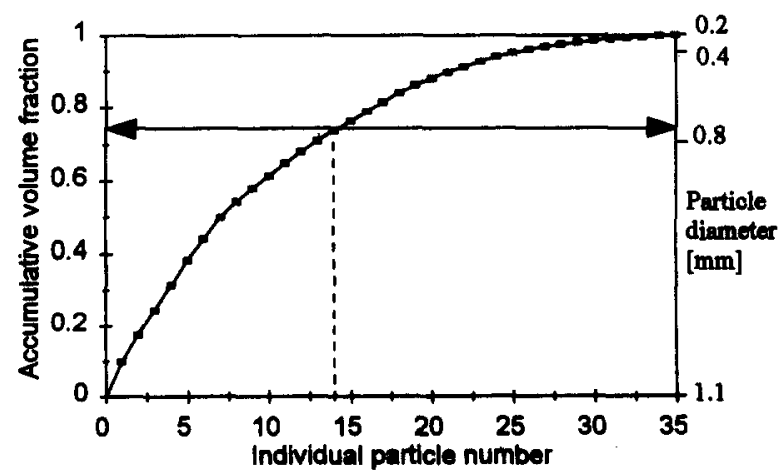

Fig. 6. The cumulative volume fraction of a sample of 35 individual Miscanthus particles from class II. All particles are descendingly sorted according to their diameter. 


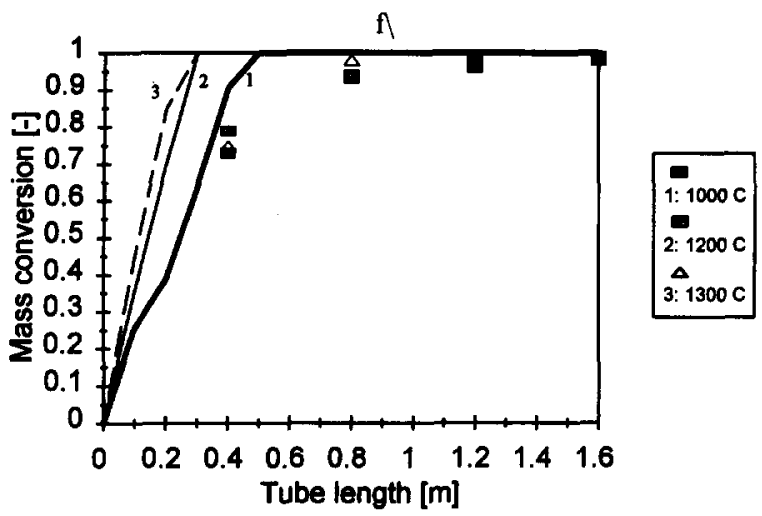

Fig. 7. The mass conversion of class I Miscanthus particles as a function of the droptube length.

decomposition rate of Miscanthus as mentioned earlier in Section 4.5. For the small class I particles, the measurement data indicate a mass conversion of $75 \mathrm{wt} \%$ at a tube length of $0.4 \mathrm{~m}$, whereas the model predicts a similar conversion at approximately $0.2 \mathrm{~m}$.

The numerical model predictions correspond to the experiments only by approximation. It must be noticed, however, that the differences between the mass conversion predictions of the numerical model and the measurement data points are caused by two effects:

- Inaccuracy of the experimental measurements. This is caused by:

- collisions of the particles with the tube wall,

- deviations in the gas phase composition during a biomass feeding interval, and

- differences in the axial gas phase temperature.

- Uncertainty of the model input parameters, such as:

- the particle size distribution,

- the random free fall orientation of cylindrical particles,

- the Miscanthus decomposition kinetics,
- the particle thermal conductivity, and

- the heat of reaction.

The difference between the measurements and model predictions shown in Fig. 7 indicates that all parameter uncertainties have some influence on the model predictions. However, it must be realised that the numerical model does not contain any fit parameters.

Results obtained with the largest class III particles are presented in Fig. 8. Here, the fit of the model predictions and the measured data points is striking, and it seems that the model predictions for large particles are less dependent on the assumed Miscanthus reaction rate and the heat of reaction compared with the model predictions for small particle devolatilisation. However, more computer simulations and a sensitivity analysis should be made to establish this fact.

\section{APPLYING THE MODEL FOR A PULVERISED COAL COMBUSTOR}

A pulverised coal combustor with many experimental facilities is Goudey Power station,

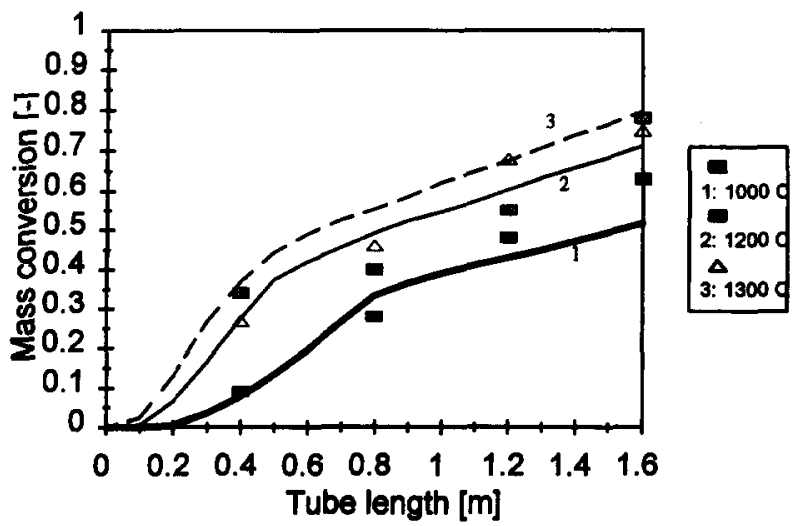

Fig. 8. The conversion of class III Miscanthus particles as a function of the droptube length. 


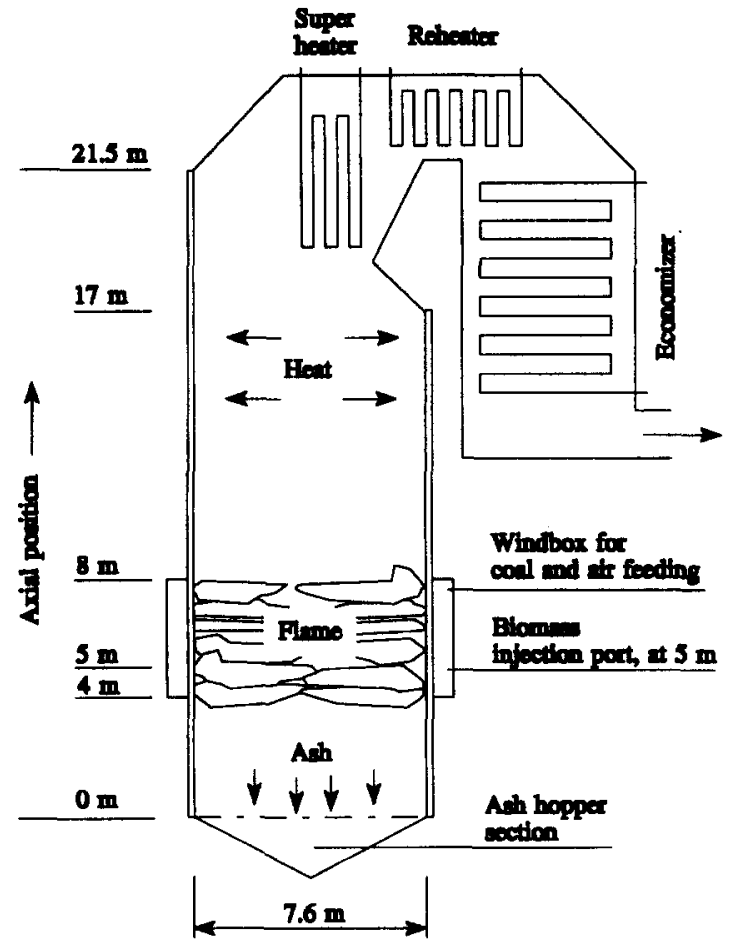

Fig. 9. Schematic representation of Goudey Station.

which has already been mentioned in the introduction of this paper. An artist's rendition of Goudey Furnace is presented in Fig. 9. The lower section of this furnace between level 1 and level 2, or at heights (respectively) of 0 and $4 \mathrm{~m}$, consists of a hopper in which ash is collected. Gas does not flow through this hopper section and the ash particles will sediment in this zero-convection environment. Pulverised coal is fed in the windbox which extends from 4 to $8 \mathrm{~m}$ in the vertical direction. In this section, a coal fireball exists and coal volatiles are released in this section. The radiant section starts at $8 \mathrm{~m}$ and extends to $17 \mathrm{~m}$ in the vertical direction. In the radiant section, the gas phase radiates its thermal energy to the furnace walls which consist entirely of heat exchanger tubes. In the radiant section, the temperature of the ash and slag particles drops below a threshold value of $1000^{\circ} \mathrm{C}$ below which the slag solidifies and does not stick to the inserted heat exchanger tubes. The heat exchanger section is placed above the radiant section at a height higher than $17 \mathrm{~m}$, and only solid particles exist in this section.

The numerical model, which has been validated with the experimental results obtained with the droptube reactor, is used to predict the effect of feeding hammermilled Miscanthus particles of different sizes. All particles are fed at a height of $5 \mathrm{~m}$ above the furnace bottom in the windbox together with the coal particles. Single particle sizes have been used in the biomass devolatilisation simulations. A total of four different particle sizes were used.

$$
\begin{array}{ll}
\text { Particle shape: } & \text { cylindrical } \\
\text { Size group 1: } & d_{\mathrm{p}}=0.5 \mathrm{~mm}, L_{\mathrm{p}}=5 \mathrm{~mm} \\
\text { Size group 2: } & d_{\mathrm{p}}=1 \mathrm{~mm}, L_{\mathrm{p}}=10 \mathrm{~mm} \\
\text { Size group 3: } & d_{\mathrm{p}}=2 \mathrm{~mm}, L_{\mathrm{p}}=20 \mathrm{~mm} \\
\text { Size group 4: } & d_{\mathrm{p}}=4 \mathrm{~mm}, L_{\mathrm{p}}=40 \mathrm{~mm}
\end{array}
$$

The applicability of the developed numerical model is clearly demonstrated in Fig. 10. Figure 10 presents the model predictions of the mass conversion of Miscanthus when co-fired with a fossil fuel in a pulverised coal station. Due to the low biomass density of Miscanthus $\left(300 \mathrm{~kg} \mathrm{~m}^{-3}\right)$ this material can be well entrained, even for a particle size up to a diameter of $4 \mathrm{~mm}$ and a cylindrical length of $40 \mathrm{~mm}$. However, these large particles devolatilise for $25 \mathrm{wt} \%$ in the radiant section which destabilises the coal flame. The radiant section of the pulverised coal combustion chamber is meant to cool the ash and slag particles in this section by the radiative

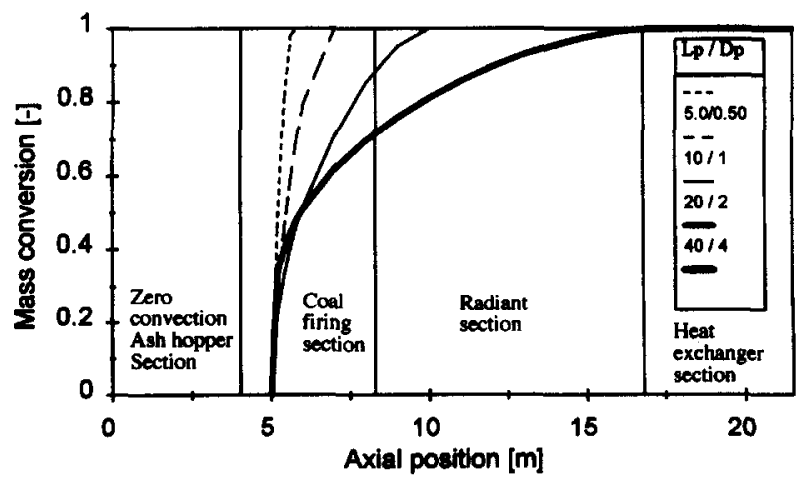

Fig. 10. The devolatilisation of Miscanthus particles injected at $5 \mathrm{~m}$ axial height. The pulverised coal combustor temperature was $1573 \mathrm{~K}$, with an upward gas-phase velocity of $7.1 \mathrm{~m} \mathrm{~s}^{-1}$. 
cooling of the particles to their solidification temperature. Releasing a large amount of Miscanthus volatiles in the radiant section leads to an upward extension of the flame, which leads to less solidifying of the molten slag particles in the radiant section. In turn, this leads to greater fouling of the heat exchangers positioned downstream.

Miscanthus particles with a diameter less than $3 \mathrm{~mm}\left(L_{\mathrm{p}} / d_{\mathrm{p}}=10\right)$ can be fired well in a pulverised coal combustor, whereas the feeding of larger Miscanthus particles leads to a geometrical extension of the flame in the vertical direction.

\section{CONCLUSIONS}

Rapid screening of the combustion behaviour of Miscanthus could be carried out successfully in the droptube furnace which has been designed, constructed and operated at the laboratory of BTG Biomass Technology Group B.V. Parameters which have been varied are:

- the droptube temperature: $1000^{\circ}, 1200^{\circ}$, $1300^{\circ}$ and $1400^{\circ} \mathrm{C}$;

- the heated droptube length: $0.4,0.8,1.2$ and $1.6 \mathrm{~m}$; and

- the particle size or sieve fraction: $0.6-1,1-2$ and $2-2.8 \mathrm{~mm}$.

With these parameters, the particle residence time in the hot zone of the reactor is $1 \mathrm{~s}$ at the maximum.

From the results of the experiments, it can be concluded that:

- according to visual inspection, partially converted Miscanthus particles have a charred envelope, which implies that these particles undergo a rapid pyrolytic change, with oxidation reactions only occurring outside the particle;

- particles of the smallest fraction (0.6$1 \mathrm{~mm}$ ) could be completely devolatilised in a 1.2 and $1.6 \mathrm{~m}$ long droptube;

- the conversion rate of crops at temperatures above $1200^{\circ} \mathrm{C}$ was over $90 \%$ at a tube length of 1.2 or longer;

- at $1400^{\circ} \mathrm{C}$, particles of the largest fraction (2-2.8 mm) of the grass-like crops also completely devolatilise at $1.6 \mathrm{~m}$ tube length.

Apart from the experimental investigation, a numerical model has been developed. Samples of Miscanthus, representing grass-like crops, have been characterised in detail. These characteristics have been used to validate the numerical model on the basis of the results from the droptube furnace. In this validation, no match-factors have been used. The numerical outcomes are in correspondence with the droptube experimental results. It is therefore concluded that the numerical model is valid.

The numerical model has been applied to predict the biomass devolatisation behaviour in a pulverised coal power station. The model predicts full conversion of energy crops for particles with a diameter smaller than $3 \mathrm{~mm}$, given a length-diameter ration of max. 10. Miscanthus particles with a diameter larger than $4 \mathrm{~mm}$ burn in the radiant section of the combustion chamber and cannot be fired in a pulverised coal station.

Acknowledgements - This research has been carried out as part of the National Research Programme on Global Air Pollution and Climate Change (NRP/GAPCC), as part of the Energy from Waste and Biomass Programme of the Netherlands Agency for Energy and Environment (NOVEM) and as part of the European Miscanthus Network, a project under the AIR Programme of the European Commission.

\section{REFERENCES}

1. Bitowft, B., Andersson, L. A. and Bjerle, I., Fast pyrolysis of sawdust in an entrained flow reactor. Fuel, $1989,68,561$.

2. Hallgren, A., Andersson, L. A. and Bjerle, I., High temperature gasification of biomass in an atmospheric entrained flow reactor. In Proceedings, Advances in Thermochemical Biomass Conversion, ed. A.V. Bridgwater, Vol. 2, p. 806. Chapman and Hall, London, 1993.

3. Germane, G. J., Eatough, C. N. and Cannon, J. N., Process data and strategies. In Proceedings, Fundamentals of Coal Combustion, ed. L. D. Smoot, p. 79. Elsevier, Amsterdam, 1993.

4. Benson, S. A., Jones, M. L. and Harb, J. N., Ash formation and deposition. In Proceedings, Fundamentals of Coal Combustion, ed. L. D. Smoot, p. 299. Elsevier, Amsterdam, 1993.

5. Chomiak, J., Combustion; a Study in Theory, Fact and Application, ed. A. K. Gupta and D. G. Lilley, Energy \& Engineering Science Series. Gordon and Breach, London, 1990.

6. Gumz, W., Kurzes Handbuch der Brennstoff- und Feuerungstechnik. Springer, Berlin, 1953.

7. Walker, P. L., Rusinko, F. and Austin, L. G., Gas reactions of carbon. Advances in Catalysis, 1959, 11, 133.

8. Knoef, H. A. M. and Prins, W., Analysis of size reduction technologies for demolition wood. Report prepared for NOVEM (Ewab program), Contract no. $355120 / 0930,1993$.

9. Wagenaar, B. M., The rotating cone reactor for rapid thermal solids processing, Ph.D. thesis, University of Tivente, The Netherlands, 1994, 36.

10. Becker, H. A., The effects of shape and Reynolds 
number on drag in the motion of a freely oriented body in an infinite fluid. Canadian Journal of Chemical Engineering, 1959, 37, 85.

11. Lapple, C. E. and Shepherd, C. B., Calculation of particle trajectories. Industrial and Engineering Chemistry 32, 605 (1940)

12. Collis, D. C. and Williams, M. J., Two-dimensional convection from heated wires at low Reynolds numbers. Journal of Fluid Mechanics, 1959, 6, 357.
13. Whitaker, S., Forced convection heat transfer correlations for flow in pipes, past flat plates, single cylinders, single spheres, and for flow in packed beds and tube bundles. AIChE Journal, 1972, 18, 361 .

14. Wagenaar, B. M., Prins, W. and Van Swaaij, W. P. M., Flash pyrolysis kinetics of pine wood. Fuel Processing Technology, 1993, 36, 291. 